\title{
A deliberação a longo prazo no espaço de visibilidade mediada: O Bolsa-Família na mídia impressa e televisiva
} Ângela Cristina Salgueiro Marques*

Resumo: Este artigo tem como objetivo analisar algumas das perspectivas e enquadramentos que alimentaram o debate mediado, entre os anos de 2003 e 2006, acerca do Programa Bolsa-Família no espaço central de visibilidade mediada - aqui concebido como o Jornal Nacional e a Folha de S. Paulo. Adotamos, assim, o seguinte procedimento de análise dos textos jornalísticos coletados: (i) identicar dos principais enquadramentos midiáticos envolvendo diferentes perspectivas sobre questões específicas; (ii) selecionar e análisar o conteúdo dos textos, a fim de obter os principais tópicos discursivos relacionados com os enquadramentos identificados; (iii) identificação das principais perspectivas discursivas presentes nos enquadramentos, analisando as citações diretas; (iv) estabelecer o tipo de relação (conflitiva, complementar, monólogica, etc) entre as perspectivas e enquadramentos identificados. Explorase o debate mediado sobre o Programa Bolsa-Família a partir da contraposição entre dois enquadramentos principais: o enquadramento da dependência (argumentos relacionados ao assistencialismo, filantropia e esmola) e o enquadramento da autonomia (pontos de vista sobre emancipação, cidadania e inclusão).

Palavras-chave: Enquadramento; deliberação mediada; jornalismo; Bolsa-Família.

\section{The long-term deliberation in mediated visibility space: The Bolsa-Familia Program in print and TV media}

Artigo recebido em: 20 de setembro de 2010 Aprovado em: 9 de outubro de 2010

\section{* Doutora em} Comunicação Social pela Universidade Federal de Minas Gerais (UFMG). Professora do Programa de Pósgraduação em Comunicação Social da Faculdade Cásper Líbero, onde lidera - Grupo de Pesquisa "Capital Social, Redes e Processos Políticos".

angelasalgueiro@gmail.com

\begin{abstract}
This article has as objective to analyze some of the perspectives and framings that configured the mediated debate, between 2003 and 2006, concerning the Bolsa-Família Program in the central space of media visibility - conceived here as composed by the Jornal Nacional and the Folha de S. Paulo. We adopt, thus, the following analytical procedure: (i) identification of the main media framings encompassing different perspectives on specific issues; (ii) selection and analysis of the texts content in order to obtain the discursive main topics related to the identified framings; (iii) identification of the main discursive perspectives within the media framings by analyzing the news direct quotations; (iv) establish the type of relation (conflictive, complementary, monological, etc.) between the identified perspectives and framings. We explore the mediated debate by opposing two major framings concerning the Bolsa-Family Program: the dependence framing (arguments related to assistencialism, philanthropy and alms); and the autonomy framing (points of view on emancipation, citizenship and inclusion).
\end{abstract}

Keywords: Framing; mediated deliberation; journalism; Bolsa-Familia Program. 

dos em diferentes arenas comunicativas devem adquirir visibilidade de modo a tornar públicos os argumentos disponibilizados para o debate. Nesse processo, a arena composta pelos meios de comunicação assume um papel crucial: é ela a responsável por editar e publicizar os fluxos discursivos oriundos das demais arenas (formais e informais), de modo a conferir-lhes amplo alcance e impacto. Assim, a atuação dos meios de comunicação no processo deliberativo está intimamente ligada à sua capacidade de conferir publicidade aos múltiplos discursos que o compõem, bem como ao seu potencial efeito de estimulação de discussões em torno das questões tornadas públicas.

Considerar o espaço dos media, e sobretudo do jornalismo, como espaço de circulação de diversas perspectivas e pontos de vista implica também reconhecer que os veículos selecionam determinados pontos de vista, privilegiando alguns segmentos sociais e salientando certos aspectos dos acontecimentos em detrimento de outros. Assim, o papel mediador dos meios de comunicação é visto sempre sob constante ceticismo, uma vez que eles dão forma à discussão a partir de astúcias e poderes que fazem parte de um repertório próprio de seleção, ordenamento e publicização (BOHMAN, 2007).

Ainda que reafirme os aspectos contraditórios dos meios de comunicação, Habermas (2006) define o sistema dos media como um espaço marcado por algumas características específicas tidas como essenciais ao fortalecimento e à manutenção das estruturas deliberativas que fazem parte da dinâmica democrática das sociedades contemporâneas. Se, por um lado, os meios de comunicação tornam públicos os discursos de atores localizados em diferentes arenas comunicativas, libertando as informações de seus contextos de origem e tornando-as acessíveis a uma vasta maioria, por outro lado, "os profissionais dos media produzem um discurso de elite, alimentado por atores que lutam por acesso e por influência” (HABERMAS, 2006, p. 417).

Alguns autores (BLUMLER \& GUREVITCH, 2000; IYENGAR, 1994; BENETT, 1990) argumentam que o discurso público que circula no espaço de visibilidade promovido pelos media está “indexado" ao conflito visível nas esferas formais do governo. Essa perspectiva pode levar, erroneamente, ao entendimento de que a deliberação mediada reflete somente a discussão que ocorre entre os atores que estão nas arenas comunicativas do "centro" do sistema político.

Adotar a perspectiva acima apontada implica dizer que as posições dos atores políticos no governo é que definiriam os parâmetros e pontos de referência para a formação dos discursos disponibilizados nos media. Neste caso, o poder dos meios de comunicação se manifestaria na atividade que seus profissionais exercem na "escolha da informação, do formato e do estilo dos programas e dos efeitos de sua difusão” (HABERMAS, 2006, p. 419), operando de modo auto-regulado e agindo em concordância com seu próprio código normativo.

Munidos de maior cautela, alguns autores (GARNHAN, 1992; DAHLGREN, 1995; PAGE, 1996; GOMES, 2004; MAIA, 2004) identificam os meios de comunicação como atores dúbios: ao mesmo tempo em que contribuem para o alargamento e a construção de espaços de discussão, estão submetidos às lógicas do mercado e das desigualdades de poder entre o público 
e os agentes mediáticos. Não há como desconsiderar, portanto, que existe no espaço de visibilidade mediada um grande escopo de assimetrias no que tange às chances desiguais de intervenção dos diferentes públicos na produção, validação, regulação e apresentação de mensagens.

Nesse sentido, a simultaneidade de acesso às informações não garante às audiências inclusividade nos debates. E mais, nem sempre a inclusão de todos os concernidos na deliberação implica em uma boa qualidade do processo. É preciso salientar aqui que tanto a quantidade de participantes quanto a qualidade da deliberação estão diretamente ligados a problemas de inclusão e de assimetrias de poder (SHAPIRO, 1999). É possível haver momentos deliberativos minimamente participativos e fortemente participativos, assim como é possível que públicos pequenos produzam deliberações mais informadas e densas que públicos ampliados (FUNG, 2004).

$\mathrm{O}$ acesso aos conteúdos discursivos e aos vários argumentos produzidos por diversos atores em diferentes contextos através dos media pode contribuir para que alguns dos problemas ligados à inclusividade sejam amenizados. Um deles relaciona-se ao fato de que, mesmo que os interessados não possam estabelecer uma interlocução face a face com todos aqueles envolvidos na discussão a respeito de determinado problema, eles podem inteirar-se dos argumentos e das razões por eles apresentados através dos media (GOMES, 2004; BLUMLER e GUREVITCH, 2000) ${ }^{1}$. Como assinalamos acima, nem todas as vozes estão representadas no espaço de visibilidade mediada. Nem por isso, a ideia de concebê-lo como espaço fundamental de mediação perde sua validade.

De acordo com Benjamin Page, os profissionais da comunicação não só permitem o intercâmbio comunicativo entre especialistas, mas "reúnem, explicam, debatem e disseminam as melhores informações e ideias disponíveis sobre as políticas públicas de modo que se tornem acessíveis a uma ampla audiência de cidadãos” (1996, p.5).

No processo deliberativo, os agentes mediáticos apresentam a capacidade de reunir as "vozes" de atores diferenciados, articulando argumentos e questões em focos temáticos de modo coerente. Como acentua Habermas (2006), o sistema dos media captura e relaciona opiniões produzidas por vários tipos de atores, desde políticos até os cidadãos comuns. $\mathrm{O}$ entrecruzamento de diferentes "vozes" e pontos de vista no espaço discursivo de visibilidade mediada nos oferece a oportunidade de avaliá-lo também como arena discursiva de conflitos e trocas de pontos de vista.

Sob esse viés, este artigo tem como objetivo analisar algumas das perspectivas e enquadramentos que alimentaram o debate mediado, entre os anos de 2003 e 2006, acerca do Programa Bolsa-Família no espaço central de visibilidade mediada - aqui concebido como o Jornal Nacional e a Folha de S. Paulo. Ao me dedicar a avaliar como as negociações discursivas são textualmente en-

\footnotetext{
${ }^{1}$ Os media possuem interesses e mecanismos próprios de produzir e editar fluxos comunicativos, mas, sem dúvida, eles disponibilizam aos indivíduos opiniões em perspectiva que apresentam contrastes entre si, de modo que o cidadão pode ter elementos múltiplos para construir a própria reflexão. Habermas (1992, p. 174) reconhece que avaliou "de maneira muito pessimista a capacidade de resistência e sobretudo o potencial crítico de um público de massa pluralista e amplamente diferenciado, que ultrapassa as fronteiras de classe em seus hábitos culturais".
} 
cadeadas pelos meios de comunicação, não me interesso somente pelo discurso jornalístico como produto mediático polifônico. Interessa-me, sobretudo, demonstrar que as disputas argumentativas delineadas no espaço mediático, se apreendidas sob uma perspectiva de longo prazo, podem evidenciar uma dinâmica deliberativa própria, na qual o discurso é empregado como forma reflexiva de posicionamento diante dos outros e de busca pela validação de enquadramentos em disputa.

\section{A deliberação mediada a longo prazo}

A deliberação pública não se restringe a um único momento ou contexto, mas constitui-se como um processo comunicativo e social continuado que depende da disposição dos participantes em recuperar, em diferentes momentos, os pontos de conflito em torno de nuances obscuras do problema em pauta, dispondo-se constantemente a retomar e a revisar as perspectivas acerca de uma questão problemática (BOHMAN, 1996). Segundo Habermas, a deliberação configura "uma rede de discursos e de negociações" (1997, p. 47) cujo caráter reflexivo refere-se ao fato de que as opiniões ficam registradas na esfera pública de tal modo que todos os participantes podem "revisitá-las" e a elas responder por meio de ações de renovada consideração e questionamento (2006, p.418).

Por isso, consideramos frutífera a concepção de deliberação a longo prazo apresentada por Dryzek (2004), uma vez que ele enfatiza a existência de uma contestação difusa de discursos na esfera pública cuja pretensão não é alterar as perspectivas dos participantes em um curto intervalo de tempo através de debates promovidos em situações excepcionais, mas aguçar sua capacidade reflexiva e aperfeiçoar suas habili-

dades críticas.

A ênfase que esse autor confere aos discursos não relega os sujeitos a um segundo plano, mas ressalta que a deliberação envolve um tipo de "comunicação anônima" dispersa na esfera pública e, como tal, é potencialmente capaz de envolver todos os cidadãos potencialmente concernidos (BOHMAN, 1996, p.178). Se acessíveis a uma ampla audiência, os pontos de vista passam a circular em diferentes esferas públicas, adquirindo a forma de uma competição entre discursos "sem sujeito" (HABERMAS, 1997, p. 22). Sob esta perspectiva, as diferentes arenas de comunicação que formam o processo deliberativo se entrecruzam de modo a originar uma "conversação pública anônima" (BENHABIB, 1996) que, estendida no tempo e no espaço, organiza diferentes pontos de vista em torno de um campo problemático. A definição e construção prática de soluções impostas por este campo requerem o envolvimento de todos os interessados, uma vez que a deliberação "deve estar aberta ao controle popular difuso e comunicativamente competente" (DRYZEK, 2004, p. 54).

A necessidade de se estabelecer conexões entre os fluxos comunicativos anônimos que circulam difusamente em diferentes esferas públicas faz dos 
meios de comunicação uma mediação essencial. Acreditamos ser possível, então, perceber e avaliar o espaço de visibilidade mediada como um contexto de entrecruzamento e enfrentamento de diferentes proposições e pontos de vista.

Se, por um lado, são vários os estudos que demonstram as contradições dos media como espaço de efetiva mediação entre diferentes setores sociais, é possível constatar, por outro lado, que são poucos os investimentos até hoje feitos para explicar como os media podem ser concebidos como locus de um processo deliberativo que pode se estender a curto ou longo prazos (MAIA, 2008; WESSLER, 2008; MARQUES, 2006). Por isso, proponho que o espaço de visibilidade promovido pelos meios de comunicação seja também entendido como contexto onde se desenvolve uma deliberação mediada fruto do conflito entre as diferentes perspectivas processadas pelos profissionais da comunicação e que se desdobra no espaço e no tempo.

\section{Enquadramentos e deliberação mediada}

Uma das principais atribuições do enquadramento delineado pelos media é a de fornecer "uma ideia organizadora central capaz de produzir sentido de eventos relevantes e sugerir o que está em questão" (GAMSON, 1989, p. 157). $\mathrm{O}$ enquadramento dispõe, assim, esquemas interpretativos que nos auxiliam a produzir e organizar, de modo coerente, sentidos acerca do mundo, de nossas relações e dos eventos que os atravessam (NORRIS, 2000). De modo mais específico, os enquadramentos mediáticos relacionam-se a padrões persistentes de cognição, interpretação e apresentação, os quais operam por meio da seleção, da ênfase e da exclusão, através dos quais os profissionais dos media organizam os discursos verbais e visuais provenientes de inúmeros contextos, sugerindo o modo "como" as pessoas devem pensar e entender determinadas questões (PORTO, 2007; TUCHMAN, 1973).

Gamson, por exemplo, aponta que as notícias televisivas estão repletas de "esquemas simbólicos que providenciam um atalho cognitivo sugerindo o fio principal da história a ser narrada. Esses esquemas estabelecem a ponte retórica através da qual fragmentos discretos de informação são dispostos em um contexto e relacionados uns com os outros" (1989, p. 158).

Os enquadramentos não são uma característica estática inerente aos textos mediáticos ou a elementos individuais psicológicos, mas "operam no sentido de organizar e estruturar a dinâmica discursiva em torno de uma questão de modo que o objeto do enquadramento não está só no conteúdo manifesto dos textos, mas na relação que argumentos aí presentes estabelecem com o que é saliente nas mentes dos públicos” (REESE, 2007, p. 151-152).

Como o objetivo principal deste texto é evidenciar o processo de enfrentamento de discursos no espaço de visibilidade mediada, julgo necessário adotar um conceito de enquadramento ligado aos mecanismos de composição de uma lógica argumentativa entre os pontos de vista que são transpostos para esse espaço.

Segundo Simon e Xenos (2000), na deliberação mediada, vários atores competem entre si para definir a situação. Cada um dos argumentos e demandas de 
validade feitos por esses atores são "abrigados" em diferentes enquadramentos de modo que uma competição entre diferentes argumentos ocasiona também uma competição entre enquadramentos. $\mathrm{Na}$ verdade, isso nos revela que os enquadramentos não podem ser reduzidos a tópicos singulares ou expressões cuja "saliência" ativa a memória das audiências. Mais do que uma "idéia organizadora central ou roteiro que provém sentido" (GAMSON e MODIGLIANI, 1989, p. 57), o enquadramento é um processo de desvelamento e construção discursiva de uma questão política ou controvérsia pública (ENTMAN, 1993).

Conceber a deliberação mediada como uma disputa entre discursos concorrentes não significa retirar os atores políticos e sociais do processo, mas, sim, enfatizar a importância da identificação dos "temas" e "enredos" (story lines) delineados pelos meios de comunicação, os quais agrupam pontos de vista, esboçam diferentes nuances do problema e orientam a justificação pública que se estabelece entre os participantes do processo deliberativo.

Para os propósitos deste trabalho, o enquadramento mediático envolve, portanto, uma atividade coletiva de definição de um problema público, na qual eixos discursivos e temáticos são responsáveis, ao mesmo tempo, por reunir argumentos afins, e por organizar as tensões entre os diferentes conjuntos formados por esses argumentos.

Os enquadramentos são princípios organizadores socialmente compartilhados que definem limites e categorias, definem também algumas idéias como pertinentes e outras não, e geralmente operam de modo a aproximar idéias relacionadas em uma rede através de um processo ativo (REESE, 2007, p.150).

Sabemos que os media trazem para seu espaço discursivo disputas existentes em outros âmbitos comunicativos, ao coletarem falas de origens diferenciadas de modo a não só aproximá-las, mas a restabelecer a conexão entre elas. No caso específico do jornalismo, diferentes vozes são acionadas de modo a compor um discurso que será endereçado a uma ampla audiência. A investigação dos modos como a atividade jornalística lida com diferentes fontes, com suas demandas e, sobretudo, com as interações entre elas torna-se extremamente relevante para o entendimento da deliberação mediada. Esta última não resulta somente da identificação de enquadramentos e pontos de vista, mas de características inerentes à própria construção do discurso jornalístico e suas formas de registro na esfera pública.

Assim, o enquadramento não pode ser confundido com um conjunto de argumentos. Ao invés disso, ele assume a forma de um eixo organizador que coloca em relação as perspectivas dos atores envolvidos na configuração de uma questão de interesse coletivo apresentando-as, seja no espaço de uma matéria jornalística, seja em um espectro de matérias consideradas ao longo do tempo.

O discurso jornalístico, ao produzir enunciados que se remetem a enunciados anteriores, estabelece entre eles elos narrativos e causais, que aproximam o "familiar" do "desconhecido" (VAN DIJK, 1999). Ao mesmo tempo, os textos são constituídos, interpretados e modificados por meio de práticas 
discursivas que, por sua vez, se configuram através de processos de tensão e conflito entre os sujeitos e seus contextos. Concebida a longo prazo, essa intertextualidade nos possibilita também apreender um tipo de troca argumentativa que permite caracterizar o espaço de visibilidade mediada como arena propícia à deliberação.

\section{A deliberação mediada a longo prazo sobre o programa Bolsa-Família}

Uma abordagem empírica que associe a construção de enquadramentos e a deliberação mediada, deve considerá-la como um processo dinâmico composto por trocas argumentativas que se dão em intervalos de tempo curtos ou longos, dependendo de variáveis como a natureza do problema em questão, o envolvimento dos atores concernidos e a publicização de perspectivas divergentes.

De modo a caracterizar a deliberação mediada sobre o Bolsa-Família a longo prazo, foram analisados um conjunto de textos jornalísticos impressos (Folha de S. Paulo) e televisivos (Jornal Nacional) referentes à primeira gestão do governo Lula (2002/2006). Como o Bolsa-Família foi criado em outubro de 2003, concentramo-nos nas matérias que foram veiculadas entre os anos de 2003 e 2006. ${ }^{2}$ Uma amostra que reunisse discursos propagados em nível nacional era desejada de modo a maximizar nossas chances de recomposição da representação do Bolsa-Família no espaço central de visibilidade mediada. Após uma primeira leitura do material coletado, foram selecionados de modo a compor um corpus analítico de 239 textos assim distribuídos:

\section{Tabela 1 - Material da mídia impressa analisado}

\begin{tabular}{cccccc} 
Veículos jornalísticos & 2003 & 2004 & 2005 & 2006 & Total de textos \\
\hline Folha de S. Paulo (diário) & 32 & 47 & 38 & 93 & 210 \\
Jornal Nacional (diário) & 2 & 11 & 4 & 12 & 29
\end{tabular}

Os textos escolhidos para análise foram aqueles que nos permitissem identificar as principais perspectivas e argumentos que, captados pelos atores mediáticos e organizados em enquadramentos específicos, revelaram o posicionamento de diversos atores em torno das questões suscitadas por esses dois programas.

Selecionados os textos, uma leitura cuidadosa foi realizada, procurando ressaltar quais as fontes, procedentes de diferentes arenas comunicativas do pro-

\footnotetext{
2 Para maiores informações sobre o programa e os valores repassados às famílias beneficiadas, consultar o site do Ministério do Desenvolvimento Social < http://www.mds.gov.br/bolsafamilia/ >.

${ }^{3}$ Grande parte dos textos da Folha de S. Paulo foi obtida no site do veículo através de seus arquivos on-line. Uma outra parte dos textos foi generosamente cedida pela professora Regina Hirata, pesquisadora do Núcleo de Estudos de Políticas Públicas (NEPP) de Campinas, que havia coletado, ao longo de três anos, recortes de matérias referentes ao Fome Zero e ao Bolsa-Família.

${ }^{4}$ As gravações do JN foram obtidas de três formas: as matérias referentes aos anos de 2003, 2004 e primeira metade de 2005 foram cedidas pelo Núcleo de Estudos em Mídia e Política (NEMP) da UnB. As matérias referentes à segunda metade de 2005 e ao ano de 2006 foram obtidas ou através de serviços de clipping ou através de gravações feitas pela própria autora deste trabalho.
} 
cesso deliberativo, foram sintetizadas pelos agentes mediáticos. A hipótese de que a deliberação mediada pode ser apreendida por meio da identificação de perspectivas que podem ser agrupadas em torno de um enquadramento específico nos permitiu avaliar a dinâmica argumentativa que entre elas se estabelece. Pretendia, assim, ampliar a análise de conteúdo realizada, evidenciando a construção de uma dinâmica de troca de argumentos entre os atores sociais e políticos que tiveram suas vozes englobadas pelos textos jornalísticos.

O exercício metodológico voltava-se, pois, para: (i) a identificação dos argumentos construídos por atores específicos situados em contextos sociais igualmente particulares; (ii) a explicitação de diferentes eixos organizadores, ou enquadramentos, os quais seriam responsáveis por reunir esses argumentos de acordo com o foco temático aos quais se referem, conferindo coerência à troca argumentativa empreendida por diferentes atores; (iii) a avaliação, através do emprego dos indicadores normativos, dos modos como os argumentos, já reunidos sob eixos organizadores, relacionavam-se reciprocamente, a fim de identificar se originaram realmente um conflito ou se, simplesmente, expressavam os posicionamentos isolados dos atores envolvidos.

A fim de destacar as principais falas presentes nos textos que compõem o

No caso do
Bolsa-Família,
a grande mídia
opta por salientar
a tensão entre
assistencialismo e
autonomia
corpus do trabalho, basei-me em sua "intertextualidade manifesta” (FAIRCLOUGH, 2001, p.136), isto é, pela presença explícita e bem demarcada das citações diretas (entre aspas) que, através do trabalho do jornalista, passam a compor o texto jornalístico.

Ao analisar os textos jornalísticos impressos e televisivos, identifiquei dois grandes enquadramentos acerca do Bolsa-Família: a) o enquadramento da dependência (abrange argumentos ligados ao assistencialismo, à filantropia e à esmola); e b) o enquadramento da autonomia (inclui os pontos de vista sobre emancipação, cidadania e inclusão). Ao mesmo tempo, procurei tornar evidente o tipo de relação (conflitiva, contestatória, contra-argumentação, monólogos, etc.) entre as perspectivas encontradas. O objetivo era verificar o tipo de relação entre as diferentes perspectivas associadas a enquadramentos diferentes. Nesse sentido, e de forma resumida, os resultados das análises podem ser encontrados nos quadros das próximas páginas.

Para recompor a dialogicidade existente entre as perspectivas discursivas é preciso estar atento ao fato de que os argumentos acionados por diferentes atores, antes de serem reconfigurados no texto jornalístico, se inscrevem em contextos sociais e em momentos históricos específicos que não podem ser desconsiderados. Assim, para apreender e analisar o processo de deliberação mediada, é necessário investir em uma proposta metodológica que não negligencie os vários aspectos intertextuais que a constituem.

O percurso analítico por nós estruturado guiou-se por dois movimentos principais: a identificação de enquadramentos organizadores de diferentes linhas argumentativas promovidas por diferentes atores (o que facilitou a identificação temática dos pontos de vista envolvidos na disputa argumentativa mediada); e a exploração da dinâmica conflitiva estabelecida entre as opiniões focalizadas por meio desses enquadramentos. É possível depreender daí que o espaço de visibilidade mediada ganha contornos de uma arena de debate atra- 


\begin{tabular}{|c|c|c|}
\hline \multirow{3}{*}{$\begin{array}{l}\text { Enquadramento } \\
\text { da dependência } \\
\text { Reúne } \\
\text { argumentos } \\
\text { contra o governo } \\
\text { baseados nas } \\
\text { noções de } \\
\text { assistencialismo, } \\
\text { manutenção da } \\
\text { pobreza, esmolas } \\
\text { e caridade. }\end{array}$} & $\begin{array}{l}\text { Principais } \\
\text { tópicos } \\
\text { discursivos }\end{array}$ & $\begin{array}{l}\text { O programa é assistencialista. } \\
\text { O programa Bolsa-Família é uma esmola. } \\
\text { O programa produz famílias dependentes do governo. } \\
\text { A bolsa não converte pobres em cidadãos, mas os torna objeto de } \\
\text { políticas. }\end{array}$ \\
\hline & $\begin{array}{l}\text { Exemplos } \\
\text { de } \\
\text { perspectivas } \\
\text { discursivas }\end{array}$ & $\begin{array}{l}\text { Argumento detonador de dissonância: "Seria tão fácil a gente } \\
\text { governar um país, um estado, uma cidade se a gente tivesse que } \\
\text { cuidar só dos pobres. Os pobres, na verdade, não dão trabalho, } \\
\text { e muitas vezes os governantes não olham pra eles, porque eles } \\
\text { não estão nas ruas fazendo passeata e fazendo protesto contra os } \\
\text { governos" (Lula, JN, 28/06/06). } \\
\text { "O Bolsa-Família está levando calorias e proteínas para os bu- } \\
\text { chinhos de nossos meninos mais pobres" (Lula, Presidente da } \\
\text { República, 24/07/06). } \\
\text { Contra-argumentos: "Achamos que matar a fome só com comida } \\
\text { é demagogia. Dar comida hoje e amanhã não resolve. E depois, } \\
\text { como é que fica?" (Leonel Brizola, PDT, 22/03/03). } \\
\text { "[Os pobres] estão deixando de ser trabalhadores para se torna- } \\
\text { rem assistidos" (Lena Lavinas, economista UFRJ, 25/12/05). }\end{array}$ \\
\hline & $\begin{array}{l}\text { Relação } \\
\text { discursiva } \\
\text { entre as } \\
\text { perspectivas }\end{array}$ & $\begin{array}{l}\text { Esse foi o enquadramento do dissenso. Atores do governo } \\
\text { tentam argumentar, diante da oposição de vários críticos, que o } \\
\text { programa começa como auxílio emergencial, mas seu principal } \\
\text { objetivo é garantir autonomia financeira para as famílias. Há um } \\
\text { constante embate dessa perspectiva com o argumento de que o } \\
\text { programa dá esmolas às pessoas. Especialistas são chamados pela } \\
\text { mídia (como vozes autorizadas e qualificadas) para emitir julga- } \\
\text { mentos sobre o programa, ou explorar argumentos que tendem } \\
\text { para uma ou outra posição. }\end{array}$ \\
\hline
\end{tabular}

vés da relação conflitiva existente entre as diversas perspectivas que permeiam não só os textos jornalísticos de um mesmo veículo, mas também aqueles publicizados por veículos diferenciados.

A análise apresentada revela que o espaço de visibilidade instaurado pela grande mídia nacional elege determinados enquadramentos, desconsiderando os contra-enquadramentos produzidos pelas famílias beneficiadas pelo BolsaFamília. Nesse espaço jornalístico há uma certa homogeneização da produção de informações que limita a diversidade de pontos de vista e de atores, embora esse espaço continue a promover uma ampliação do leque de perspectivas tornadas públicas para um maior esclarecimento acerca das questões em debate. Não obstante, vimos que, no caso do debate mediado acerca do Bolsa-Família, a grande mídia opta por salientar a tensão entre assistencialismo e autonomia, deixando de lado discussões ligadas, por exemplo, aos direitos humanos, às injustiças sociais e à inserção sócio-econômica dos cidadãos.

A palavra das pessoas beneficiadas pelo programa aparece no espaço de visibilidade diluída em uma diversidade de "casos" pontuais propensos a receber um tipo de tratamento padronizado e um tipo de atenção social resignada. Por um lado, é possível dizer que o testemunho dos beneficiados também expressa uma perspectiva capaz de informar o debate. Por outro lado, a dificuldade dessas pessoas de transformar sua perspectiva em razões capazes de fazer frente

\footnotetext{
${ }^{5}$ LEITE, Pedro Dias; GUIBU, Fábio. "Lula diz que, sem reforma, novos escândalos surgirão", Folha de S. Paulo, Brasil, 24/07/06, p.A4

6 GOIS, Antônio; GRABOIS, Ana Paula. "Brizola critica Fome Zero e diz que PDT dará 'apoio independente' a Lula", Folha de S. Paulo, Brasil, A6, 22/03/03.

7 GOIS, Antônio. "Pobres se distanciam de ricos e dependem mais do governo", Folha de S. Paulo, Brasil, 25/12/05, p.A4
} 


\begin{tabular}{|c|c|c|}
\hline \multirow{3}{*}{$\begin{array}{l}\text { Enquadramento } \\
\text { da autonomia } \\
\text { Apresenta } \\
\text { argumentos } \\
\text { favoráveis à } \\
\text { emancipação das } \\
\text { famílias benefi- } \\
\text { ciaries por meio } \\
\text { da criação de no- } \\
\text { vos empregos, } \\
\text { fortalecimento } \\
\text { da cidadania, } \\
\text { aumento de } \\
\text { medidas de } \\
\text { inclusão, etc. }\end{array}$} & $\begin{array}{l}\text { Principais } \\
\text { tópicos } \\
\text { discursivos }\end{array}$ & $\begin{array}{l}\text { O programa garante uma ajuda emergencial aos pobres. } \\
\text { O programa Bolsa-Família torna possível a emancipação das famí- } \\
\text { lias. } \\
\text { O benefício do programa é uma ajuda complementar a ações locais. } \\
\text { O programa, ao minimizar a miséria, garante a cidadania às pessoas } \\
\text { pobres. } \\
\text { O programa garante uma ajuda emergencial aos pobres. } \\
\text { O programa Bolsa-Família torna possível a emancipação das famí- } \\
\text { lias. }\end{array}$ \\
\hline & $\begin{array}{l}\text { Exemplos } \\
\text { de } \\
\text { perspectivas } \\
\text { discursivas }\end{array}$ & $\begin{array}{l}\text { Argumento detonador de dissonâncias: "Se o PSDB fez um exército } \\
\text { de famintos pelo Brasil, o PT, que prometeu resolver os problemas, } \\
\text { veio para dar esmolas a esses famintos." (Paulo Maluf, PP, na época } \\
\text { candidato à Prefeitura de São Paulo, 04/09/04). } \\
\text { Contra-argumentos: "Ninguém quer ficar dando bolsa, cartãozinho. } \\
\text { O que nós queremos é que a população brasileira pobre possa estar } \\
\text { incluída. Para isso ela precisa de salário e de trabalho" (Benedita da } \\
\text { Silva, na época Ministra da Assistência Social, } 28 / 03 / 03) .{ }^{9} \\
\text { "Eu queria podê, assim, tê o meu trabalho, o meu marido tê o } \\
\text { trabalho dele, prá gente podê ajudá a mantê a família." (Glória, } \\
\text { beneficiária). }{ }^{10}\end{array}$ \\
\hline & $\begin{array}{l}\text { Relação } \\
\text { discursiva } \\
\text { entre as } \\
\text { perspectivas }\end{array}$ & $\begin{array}{l}\text { Atores do governo tentam legitimar uma nova proposta de política } \\
\text { social, enquanto atores da oposição levantam controvérsias a fim de } \\
\text { deslegitimizar as proposições feitas por seus adversários e, não raro, } \\
\text { descredibilizam os próprios adversários. }\end{array}$ \\
\hline
\end{tabular}

às demais razões sustentadas pelos demais interlocutores aponta sua fragilidade política. Essa fragilidade contribui para que os beneficiários não sejam reconhecidos como interlocutores moralmente capazes de apresentar e defender publicamente suas razões, além de reproduzir o tratamento paternalista à eles dispensado pelo Estado.

As incoerências presentes no discurso de Lula sobre o Bolsa-Famíla apontam que, ao mesmo tempo em que ele assume a necessidade de criar espaços onde os pobres possam expressar e discutir suas necessidades e como melhor solucioná-las, ele preza sua posição paternalista de defensor dos cidadãos que não sabem organizar-se para lutar por seus direitos. Essa postura reflete a ideia de que o gorverno não sabe interpretar as demandas formuladas nas arenas periféricas do processo deliberativo. Isso gera a impressão de que as necessidades dos pobres não precisam ser discutidas ou negociadas, uma vez que o presidente diz saber o que é melhor para eles, antes mesmo que expressem o próprio desejo.

Há, contudo, arenas marginais do processo deliberativo nas quais as pessoas pobres definem suas necessidades e prioridades; reúnem e escolhem alternativas para enfrentar a pobreza; descobrem e se informam sobre direitos; questionam as atitudes impositivas do governo, e os preconceitos perpetuados pelos media. Argumento que, para a consolidação da democracia, não importam somente os contextos formais de deliberação política ou os contextos mediados de troca discursiva. É principalmente nos contextos cotidianos de vivência que as pessoas se implicam em conversações que podem ajudá-las a

\footnotetext{
${ }^{8}$ CHRISTOFOLETTI, Lilian. "PT dá esmola a famintos, diz Maluf", Folha de S. Paulo, Brasil, A4, 04/09/04.

9 CARIELLO, Rafael. "Ninguém quer ficar dando cartãozinho, diz Benedita", Folha de S. Paulo, Brasil, 28/03/03.

10 Jornal Nacional, 01/1 1/05.
} 
identificar e a esclarecer suas reais necessidades, questionando as perspectivas sustentadas por atores políticos e mediáticos.

\section{Considerações finais}

Os enquadramentos devem ser concebidos como um dentre vários dos recursos estruturantes dos processos de organização da deliberação pública mediada. Eles nos permitem ver como os media lidam com diferentes fontes e seus proferimentos através da construção de um enunciado próprio.

É preciso, portanto, não perder de vista o fato de que nem todos os participantes conseguem ter seus argumentos ou demandas de validade englobadas por um enquadramento mediático. A competição entre enquadramentos diferentes não garante que lados opostos irão se enfrentar em igualdade de forças, ou que as audiências serão expostas, de maneira igual e simultânea, a enquadramentos alternativos igualmente persuasivos (PORTO, 2007; MARQUES, 2006). De acordo com Habermas (2006), a esfera pública mediada é mais porosa e acessível a dois tipos particulares de atores: os profissionais mediáticos e os políticos. Ele ainda destaca os cinco principais conjuntos de atores que aparecem com maior frequência no palco virtual (virtual stage) de uma esfera pública estabelecida pelos media: lobistas, advogados, especialistas, intelectuais e empreendedores morais (geram atenção pública para questões supostamente negligenciadas).

Neste trabalho, foram identificados os principais enquadramentos aos quais os atores (fontes) se reportam para construir seus argumentos, do que no enquadramento geral que fornece o "tom" às matérias. Não desprezo o valor cognitivo deste último, mas busquei tornar evidente o modo através do qual a deliberação mediada organiza-se a partir de um confronto entre argumentos enfeixados e focalizados sob determinados enquadramentos. Sob esse viés, um ator que endereça sua perspectiva sob um dado problema ao espaço de visibilidade mediada deve filiá-la a um enquadramento específico, demonstrando conhecer que, no processo deliberativo mediado, "as informações e argumentos são elaborados sob a forma de opiniões focalizadas” (HABERMAS, 1997, p. 94).

O papel organizador dos enquadramentos permite que extrapolemos o contexto de uma notícia específica para percebermos como os argumentos presentes em diferentes falas, apresentadas por matérias jornalísticas e, até mesmo, por veículos distintos, podem ser aproximados, contrapostos ou sobrepostos, de modo a evidenciar uma dinâmica típica da deliberação mediada. $\mathrm{O}$ enquadramento, portanto, orienta a construção intertextual da notícia, favorecendo o entrecruzamento de diferentes perspectivas que se interrogam reciprocamente. 


\section{Referências bibliográficas}

BENHABIB, Seyla (ed.). Democracy and Difference - contesting the boundaries of the political. Princeton: Princeton University Press, 1996.

BENNETT, Lance. "Toward a Theory of Press-State Relations". Journal of Communication, v.40, 1990, p. 103-125.

BLUMLER, J. \& GUREVITCH. "Rethinking the Study of Political Communication". In: Mass Media and Society. Oxford: Oxford University Press, 2000, p.120-154.

BOHMAN, James. Public Deliberation: pluralism, complexity, and democracy. Massachusetts: Mit Press, 1996.

BOHMAN, James. "Political Communication and the epistemic value of diversity: deliberation and legitimation in media societies". Communication Theory, v.17, p.348-355, 2007.

DAHLGREN, Peter. Television and the Public Sphere: citizenship, democracy and the media. London: Sage Publications,1995, p.71-119.

DRYZEK, John. "Legitimidade e Economia na democracia deliberativa". In: COELHO, Vera Shattan; NOBRE, Marcos (orgs.). Participação e Deliberação: Teoria Democrática e Experiências Institucionais no Brasil Contemporâneo. São Paulo: Ed. 34, 2004, p.41-62.

ENTMAN, Robert. "Framing: towards clarification of a fractured paradigm". Journal of Communication, 43(4), 1993, p. 51-58.

FAIRCLOUGH, Norman. Discurso e Mudança Social. Trad.: Izabel Magalhães. Brasília: Editora UnB, 2001.

FUNG, Archon. "Receitas para esferas públicas: oito desenhos institucionais e suas consequências". In: COELHO, Vera Shattan; NOBRE, Marcos (orgs.). Participação e Deliberação: Teoria Democrática e Experiências Institucionais no Brasil Contemporâneo. São Paulo: Ed. 34, 2004, p.173-209.

GAMSON, William. "News as framing". American Behavioral Scientist, v.33, n.2, 1989, p.157-161.

GAMSON, William; MODIGLIANI, Andre. "Media discourse and Public Opinion on Nuclear Power; a constructionist approach". American Journal of Sociology, v.95, n.1, 1989, p. 38-107.

GARNHAM, Nicholas. "The Media and the Public Sphere”. In: CALHOUN, C. (ed). Habermas and the Public Sphere. Cambridge: MIT Press, 1992.

GOMES, Wilson. Transformações da política na era da comunicação de massa. São Paulo: Paulos, 2004.

HABERMAS, J. "Political Communication in Media Society - does democracy still enjoy an epistemic dimension? The impact of normative theory on empirical research". Communication Theory, v.16, 2006, p. 411-426.

HABERMAS., Jürgen. "Further Reflections on the Public Sphere". In: CALHOUN, Craig (ed.). Habermas and the Public Sphere,1992, p.421-461.

HABERMAS, Jürgen. Direito e Democracia: entre facticidade e validade. Vol II. Trad. Flávio Beno Siebeneichler. Rio de Janeiro: Tempo Brasileiro, 1997. IYENGAR, Shanto. Is Anyone Responsible? How television frames political issues. Chicago: University of Chicago Press, 1994.

MAIA, Rousiley Celi Moreira (org.). Mídia e Democracia Deliberativa. São Paulo: FGV, 2008.

MAIA, Rousiley Celi Moreira. "Visibilidade e accountability: o evento do 
ônibus 174"- texto apresentado no GT Comunicação e Política, XII COMPÓS - São Bernardo do Campo, Universidade Metodista de SP, 22 a 25 de junho de 2004.

MARQUES, Ângela Cristina Salgueiro. "Dimensões da Autonomia: o programa bolsa-família no discurso midiático e na fala das beneficiárias". Contracampo, Niterói, v.14, 2006, p.126-162.

PAGE, Benjamin. Who deliberates? Mass Media in Modern Democracy. Chicago : The University of Chicago Press, 1996.

PORTO, Mauro. "Framing Controversies: Television and the 2002 Presidential Election in Brazil". Political Communication, v.24, p.19-36, 2007.

REESE, Stephen. "The framing project: a bridging model for media research revisited". Journal of Communication, v.57, p. 148-154, 2007.

SHAPIRO, Ian. "Enough of Deliberation: politics is about interests and power”. In: MACEDO, Stephen (ed.). Deliberative Politics: essays on democracy and disagreement. Oxford: Oxford University Press, 1999, p. 28-38.

SIMON, Adam e XENOS, Michael. "Media Framing and Effective Public Deliberation”. Political Communication, v.17, n.4, 2000, p.363-376.

TUCHMAN, Gaye. "Making news by doing work: routinizing the unexpected". American Journal of Sociology, v.79, 1973.

VAN DIJK, Teun. "Discourse and the denial of Racism". In: JAWORSKI, Adam; COUPLAND, Nikolas (eds.). The Discourse Reader. London: Routledge, 1999, p.541-558.

WESSLER, Hartmut. Investigating Deliberativeness Comparatively, Political Communication, v.25, 2008, p.1-22. 